\title{
The learning effects of brands: Determined through Markovian analysis of brand switching
}

\author{
Dilip Roy \\ Centre for Management Studies \\ University of Burdwan, Burdwan-713104, India \\ E-mail: dr.diliproy@gmail.com
}

Rupam Tewari

Business Administration, ISB, Salt Lake, Sector V, Kolkata, India

E-mail: tewari.rupam@gmail.com

\author{
Anupama Tewari \\ Business Administration, Dr. B C Roy Engineering College \\ Fuljhore, Durgapur-713206, India \\ E-mail: anupama.tewari@rediffmail.com
}

\begin{abstract}
It is the learning effect that gives rise to brand loyalty for a repeat purchase product and is an important consideration in today's competitive market. This paper aims at determining the learning effects of brands using Markovian analysis.

The Markovian study of market stability involves construction of two transition probability matrices from the loss-gain matrix depicting the brand switching behavior of the customers in the forward and backward directions and the projection of those matrices over time.

From the market stability in the forward and backward directions the learning effects, expressed in terms of acceptance line and rejection line, have been analytically obtained. For demonstration purpose, a set of information, available in the literature, on brand switching in the Indian oral care market has been used and learning effects have been empirically determined along with a discussion on managerial implications of the same.

Since we have presented a generic approach it can be applied for any product field of any country subject to constraint that Markovian stability should be there in both forward and backward directions.
\end{abstract}

Keywords: Learning effects, Markovian analysis, forward and backward stability acceptance line, rejection line. 


\section{Introduction}

1.1 Importance of Marketing: According to Ansoff (1987) marketing is an entrepreneurial activity. For every business organization, marketing activity plays the role of window through which one can have the glimpses of the outer environment. However, the process of looking at the external environment and trying to establish a link with the inner environment must be a focused one. Given a plethora of environmental parameters, strategic planners must decide upon the key issues to be studied during the environmental analysis and diagnosis (see Hill and Jones, 1992). Over the years, researchers have found that the market-cum-competitive factor is one of the most important environmental factors to be scanned, with high priority and caution, for arriving at a strategic decision. Within the market and competitive factor, sub factors of importance are market size, market growth rate and degree of competition. Out of these three sub-factors, an organizational performance gets markedly reflected through its market share. Caminal and Vives (1996) have pointed out why market share matters. In fact, it has been observed by various researchers that market share may not be the best measure of market performance but nevertheless it is the least imperfect measure of the organizational performance in the market place. Relative market share, according to Schwalbach (1991), is the resultant effect of competition in the market and captures the best possible information about the competition. It is either directly or indirectly related to various other measures of organizational performance, which are of strategic importance.

The degree of competition in a product field, measured in terms of entropy or Euclidean distance, also makes use of market share values to describe the extent of market dynamics. As a result, to study the market and competitive factor, and organizational performance, an environmental analyst should carry out in-depth study on the market shares of the leading brands of the industry under consideration. Another concept that follows at the heels of market share and invites attention is learning effect. This needs some elaboration.

Importance of learning: We know that to gain market share a firm may load its product through its distribution network. But merely pushing the offer of the company is not sufficient to enjoy the favor of the customers. Along with the concept of push, the concept of pull is important. Probably the later is more important than the former for a market with high involvement and high potentiality for brand loyalty (see Kotler, 2000, pp 567). In spite of the company's promotional activities one has to heavily depend upon customer's choice and preferences to increase its sales. This is because the final selection of the product depends on how well the product fits into customers' needs and preferences. The obvious question that arises is how to judge the fitness of an offer. If the experience after using a brand is good, the customer may go for repeat purchase. On the contrary, if the experience after using a brand is bad, the customer may not go for repeat purchase of that brand. This is what learning effect is.

According to Kotler (2000, pp 173), learning involves changes in an individual's behavior arising from experience. It moulds the minds of the customers in such a way that even a temporary withdrawal of promotional activities may not affect the sales for a few months. According to Villas-Boas (2004), in many markets, consumers, while using the product, can 
learn about the valuation of the product. Subsequently, in future periods, there will be an informational advantage in the sense that a consumer will get acquainted with more information about the products the consumer has tried than about the products she/ he has not tried.

It is propounded that this informational edge may benefit the products that are purchased first as because consumers may show brand loyalty. The concept is that after using a product and determining its valuation, a consumer would like to use that offer whose valuation she/ he knows better, rather than the offers whose valuations remain doubtful because of limited information. In this sense, firms may like to compete severely for consumers to try their products earliest. Similarly, Bain (1956) had pointed that this informational advantage may work as an obstacle for entry as the consumers tend to be loyal to the established brands. As noted in Wernerfelt (1991): "You know the quality of your current brand, so why take a risk of changing”. These are all effects of learning. Thus, learning effect must be closely reviewed to get an idea about need-offer matching.

How to study the learning-effect: In case the offer of the company falls under the repeat purchase category, core parameter of interest for the company will be brand loyalty. Brand loyalty determines the size of the assured market, highlights the need for market penetration and the feasibility of the same. To examine the brand loyalty, the basic information, one needs is again the market share vector.

If we take a closer and critical look at the market share vector, we may notice that it is governed by two variations - causal and random. Random variations arises out of large number of causes mostly unknown and uncontrolled. Hence, the study of causal variation assumes importance. One such assignable cause of variation may be viewed as the learning effect of a brand. Since, market share imbeds into it the effects of learning and their interactions, it may be possible to identify at what rate the brand learning is taking place and in which way it is shaping the brand switching behavior of the customers. Here comes the need for measuring learning effects. Brand learning models are structural attempts to meet this need.

1.2 Learning Models: The conceptual framework of brand learning is made of two important issues, viz., acceptance and rejection of the brand. In a linear learning model, developed by Bush and Mosteller (1955, see Lilien et al, 1999, p. 49) and applied by Kuehn (1962), the main problem therefore is to identify the acceptance and rejection lines so as to determine with what chance previous brands is going to be accepted in the next purchasing occasion. In probabilistic language, one is interested in determining the likelihood that the buyer will remain loyal and not shift to some other brand. The point of intersection between purchase operators, i.e. the acceptance line, and the axes bisector gives rise to incomplete habit formation indicating that some chance remains that customer may buy another brand. Similarly the point of intersection between rejection operator, i.e. the rejection line and the axes bisector gives rise to incomplete habit extinction indicating the positive probability with which a consumer may buy a previously neglected brand. 
Carman(1966), Kuehn and Rohloff(1967) studied learning model and its effect using real life data and on evaluation of promotional activities. Lawrence(1975) and Wierenga(1974) made use of learning model in different contexts. However, Leefiand and Boostra (1982) indicated a few limitations of the learning model.

Latter, Slater and Narver (1994) examined the information requirement of a learning model. According to them, this requires obtaining information about customers and efficiently viewing the information from a total business perspective. Their model portrays the state in which consumers acquire knowledge about the product they make use of in the first period and then make a choice in the second period about the competing products. This latter choice is conditional, given what they have learned in the first period. If the distribution of valuations for each product is negatively skewed, a firm can earn profit in the future from having a greater market share today. Reverse is the case for positively skewed distribution. These are brand loyalty characteristic. Under negative skewness, two aftereffects can be noticed: one is forward-looking consumers are less price sensitive than prejudiced consumers, and this shifts the market balance towards higher prices. Another is forward-looking firms who feel that they can be better off in the future from having a higher market share in the current period and can participate more intensely in respect of price. They have also characterized the importance of consumer learning effects on the market outcome.

In various studies since Guadagni and Little (1983), the researchers have noted that consumers tend to exhibit stochastic loyalty to the products they purchased most recently. Danaher et al. (2003) argued that this stochastic loyalty seems to be stronger for online purchases and looked at those firms' strategic decision-making problem with a well-knitted explanation for brand loyalty.

1.3 Proposed Work: Keeping the above discussions in the backdrop, the current work can be seen as formalizing the switching process by which knowledge about the previously bought products enters into the consumers' choice-decision. This involves a consideration of forward-looking behavior of both consumers and firms and the interaction among all these forward-looking market players, establishing an explanation for how firms create and exploit brand loyalty. Here comes the role of acceptance line of learning of the brand-switching model.

Alternatively, a consumer, after the trial of a brand, may find it to have a weak valuation. In such a case, she/ he may choose to buy a competitor's brand, knowing fully well that the valuation of that previously unused brand may be more uncertain. In fact, whether a firm becomes better or worse off from having greater initial demand is dependent on the skewness of the prior distribution of valuations. Here comes the role of rejection line of learning and the same can be studied from backward stationary approach of the brand-switching model.

To be more specific, we have undertaken a study on Markovian learning effect. The objective of our study is to prepare a theoretical framework for the determination of learning effects by taking into consideration forward and backward states of stability in the market. This search for stability and its use in estimating the learning effect will further strengthen the Markovian approach by determining and forecasting the brand shares of the players of an industry due to 
learning. To demonstrate the merit of this study, we propose to make use of a dataset on brand switching behavior of the customers in the Indian toothpaste market and determine the learning effects. The applicability of the learning results has been further studied through an independent survey work to analyze their managerial implications.

\section{A bird's eye view of the Markovian analysis}

2.1 Markov Models: Markov model, a special type of stochastic process (see Ross 1983) that can be described in terms of a random variable indexed with respect to time. This variable can be either discrete or continuous. It is being widely used for future prediction. Conceptually, Markov analysis takes into consideration a sequence of events and analyzes the future chance of occurrence of an event based on the occurrence of the immediate predecessor. In this sense, behavior of a system in each state is of limited memory i.e. the future state of the system depends only on its present state. But through repeated application of this analysis one can generate a new sequence of random but related events. In case of examining brand-switching behavior in a product field, Markovian models can be employed to ascertain the future market shares of the brands based on present brand switching behavior. It gives a clear view of the relative market shares of the brands and hence one can arrive at the nature and extent of competition in the market.

2.2 Different application of Markov Models: Different researchers in different directions have explored the strength of the Markov analysis. It is frequently used in brand switching, reliability, maintainability and safety works where events such as purchase failure or repair module can occur at any point of time. Markov chain methods have also become very effective in generating a series of random numbers to accurately reflect very complicated probability distributions in simulation study. It is called Markov Chain Monte Carlo method (see Robert and Casella, 2004). In the recent past, this has widened the applicability of Bayesian inference method. The use of Markov Chain can also be noticed in the field of biological modeling, especially in processes that are closely comparable with the biological populations. In the recent past Markov Chain method has been extensively applied to Geo-statistical problems.

In view of so many applications of Markov model and a few, not too justifiable, criticisms, we feel that the domain of application of Markov Model should be further extended. With this backdrop, we propose to open up another field of application of Markov analysis by linking the Markov analysis with Learning model and determining the learning effects of a brand through Markovian analysis.

\section{Mathematical representation of Markovian learning}

3.1 Notations and model: Let the loss gain matrix for $\mathrm{k}$ brands in a product field over two purchase occasions be denoted by

$$
\mathbf{F}=\left(\left(f_{i j}\right)\right),
$$


where $f_{i j}$ is the number of customers switching over to $\mathrm{j}$-th brand on the second occasion from the ith brand on the first occasion. Denoted by $f_{\text {io }}$ the number of customers preferring ith brand on first occasion and by $f_{o j}$ the number of customer preferring j-th brand on the second occasion. Then

$$
f_{i_{0}}=\sum_{j=1}^{k} f_{i j}, f_{0 j}=\sum_{i=1}^{k} f_{i j} \text {, for all } \mathrm{i} \text { and } \mathrm{j} \text {. }
$$

Let us consider two transition matrices $T^{F}$ and $T^{B}$, for forward and backward prediction of brand switching behavior, where

$$
\begin{gathered}
T^{F}=\left(\left({ }^{\alpha_{i j}}\right)\right)^{k^{* k}} \\
T^{B}=\left(\left({ }^{\beta_{i j}}\right)\right) k^{* k}
\end{gathered}
$$

where $\quad \alpha_{i j}=\frac{f_{i j}}{f_{i o}} \quad \mathrm{i}, \mathrm{j}=1,2, \ldots \ldots \mathrm{k}$

$$
\beta_{i j}=\frac{f_{i j}}{f_{o j}} \quad \mathrm{i}, \mathrm{j}=1,2, \ldots \ldots \mathrm{k}
$$

It is easy to note that $T^{F}$ and $T^{B}$ so defined will be probability matrices for studying the forward and backward movements respectively. Then based on the $T^{F}$ we can determine a future stability in the market with stable market share as $\mathbf{X}^{\mathbf{F}}$ satisfying the relationship

$$
\left(\mathbf{X}^{\mathbf{F}}\right)^{\prime}=\left(\mathbf{X}^{\mathbf{F}}\right)^{\prime} T^{F} \text { or } \mathbf{X}^{\mathbf{F}}=\left(T^{F}\right)^{\prime} \mathbf{X}^{\mathbf{F}}
$$

Similarly, based on $T^{B}$ we can examine the conceptual backward stability in the market share as $\mathbf{X}^{\mathbf{B}}$ satisfying the relationship

$$
\mathbf{X}^{\mathbf{B}}=T^{B} \mathbf{X}^{\mathbf{B}}
$$


Then for the $\mathrm{i}^{\text {th }}$ brand incomplete habit formation can be viewed as $X_{i}^{F}$ and incomplete habit extinction can be viewed as $X_{i}^{{ }^{B}}$.

Introducing the dimension of time, we have under the linear learning model the acceptance line to be of the form

$p_{j}^{t+1}=\alpha_{1}+\lambda_{1} p_{j}^{t}$

so that under the state of forward stability

$\chi_{j}^{F}=\alpha_{1+} \lambda_{1} x_{j}^{F}$

Eliminating $\alpha_{1}$ from the above two equations we observe that

$\chi_{j}^{F}=\left(p_{j}^{t+1}-\lambda_{1} p_{j}^{t}\right)+\lambda_{1} x_{j}^{F}$

which implies that

$\chi_{j}^{F} p_{j}^{t+1}=\lambda_{1}\left(x_{j}^{F}-p_{j}^{t}\right)$

$$
\text { Or, } \lambda_{1}=\frac{x_{j}^{F}-p_{j}^{t+1}}{x_{j}^{F}-p_{j}^{t}} \quad \text { and } \quad \alpha_{1}=\left(p_{j}^{t+1}-\lambda_{1} p_{j}^{t}\right)
$$

These determine both $\alpha_{1}$ and $\lambda_{1}$, and thereby the linear learning effect of acceptance.

Similarly, introducing the dimension of time, we have under the linear learning model the rejection line to be of the form

$p_{i}^{t+1}=\alpha_{2+} \lambda_{2} p_{i}^{t}$

so that under the state of backward stability

$x_{i}^{B}=\alpha_{2+} \lambda_{2} x_{i}^{B}$.

Eliminating $\alpha_{2}$ from the above two equations we observe that

$x_{i}^{B}=\left(p_{i}^{t+1}-\lambda_{2} p_{i}^{t}\right)+\lambda_{2} x_{i}^{B}$, 
which implies that

$x_{i}^{B} p_{i}^{t+1}=\lambda_{2}\left(x_{i}^{B}{ }_{-}^{t}\right)$

$$
\text { Or, } \lambda_{2}=\frac{x_{i}^{B}-p_{i}^{t+1}}{x_{i}^{B}-p_{i}^{t}} \text { and } \alpha_{2}=p_{i}^{t+1}-\lambda_{2} p_{i}^{t} \text {. }
$$

These determine both $\alpha_{2}$ and $\lambda_{2}$, and thereby the linear learning effect of rejection.

To demonstrate the above procedure, we propose to consider a market survey result in the field of oral care.

\section{An empirical study}

4.1 Product field: Our choice of the product field is the Indian oral care market with offers of the form of a powder or a gel or a paste. In a developing country like India, where one-sixth of the world's population reside, the toothpaste/ gel market potential is enormous. At present, the Indian oral care market is built around urban India, mainly. People in rural India still seem to prefer using a tree twig to a tube of paste or a gel. Today, branded toothpaste penetration stands at $76.8 \%$ in urban India as compared to only $37.1 \%$ in rural India (Source: NRS 2002) and hence the players of this oral care market may like to know the learning effects of their brands and plan future course of action accordingly.

4.2 Data Collection: While examining the suitability of brand switching model Roy and Lahiri (2004) considered some test procedures. In that context they collected information on Brand switching behavior on fast moving consumer goods namely sanitary napkin, toothpaste, soap and shampoo. For our present study, we propose to consider the brand switching behavior in respect of toothpaste only. The corresponding loss gain matrix for brand switching in toothpaste covering 400 individuals is given in table I

(Insert table I here)

4.3 Determination of learning effect: From the table I, we obtain the joint probability matrices for examining the forward and backward stabilities. Table II will be of use to ascertain the forward stability. Table III will be of use to ascertain the backward stability.

(Insert table II and table III here)

Through forward and backward analyses based on equations (1) and (2) we get stable market shares of the different brands of toothpastes. We have arrived at these solutions by making use of the first phase of two-phase method included in TORA software. The stable market shares are presented in table IV. 
(Insert table IV here)

From the Table IV we may observe that for Closeup the difference between the forward and backward steady state market shares is of highest positive value and for Pepsodent the difference between the forward and backward steady state market shares is of highest negative value. It may also be observed that for Colgate and Colgate gel, taken together, the difference between the forward and backward steady state market shares is nearly constant (= 0.0030). Thus, we may conclude that the market share of Close-up is increasing at the cost of the market share of Pepsodent. This means Close-up has a positive learning effect and Pepsodent has a negative learning effect. To estimate these learning effects, we can then write equation (3) for Close-up, and equation (4) for Pepsodent as follows:

Close-up: $\quad \lambda_{1}=\frac{x_{j}^{F}-p_{j}^{t+1}}{x_{j}^{F}-p_{j}^{t}}=(0.2033-0.1925) /(0.2033-0.1775)=0.4186$,

and

$\alpha_{1}=\left(p_{j}^{t+1}-\lambda_{1} p_{j}^{t}\right)=0.1182$

Pepsodent: $\quad \lambda_{2}=\frac{x_{i}^{B}-p_{i}^{t+1}}{x_{i}^{B}-p_{i}^{t}}=(0.1143-0.08) /(0.1143-0.1)=2.398$,

and

$$
\alpha_{2}=p_{i}^{t+1}-\lambda_{2} p_{i}^{t}=-0.1598
$$

Thus, the final estimation of the habit formation and habit extinction for Closeup and Pepsodent respectively can be expressed in terms of the linear learning model for acceptance for Closeup as:

$$
p_{j}^{t+1}=0.1182+0.4186 p_{j}^{t}
$$

and the linear learning model for rejection of Pepsodent as:

$$
p_{i}^{t+1}=-0.1598+2.398 p_{i}^{t}
$$

Also, from these linear equations, we can get the rates of positive and negative learning in terms of the slopes of the respective curves.

4.4 Managerial implications: In the early 1970s, Colgate was the lead player of the Indian oral care market - to the extent of being a generic name to the toothpaste category. Family health brands were the order of those days. This trend is very much seen in the rural and semi-rural areas, even now. Colgate still enjoys a solid loyalty with emotional attachment. Continuous product modification and regular communication have forced the other players to 
fight amongst themselves for the share of the left over part of the market. Our Markovian analysis on learning upholds these observations in unequivocal terms.

Where changes are prominent are Pepsodent and Close-up. It may be observed from the Markovian analysis that Pepsodent is gradually loosing ground due to negative learning-effect. Specially conducted personal interviews have revealed that many users have stopped using Pepsodent because they feel they have the toothpaste with more fluoride and peroxide and baking soda. These may negatively affect the teeth in the long run. Some college going users have reported that they got initially impressed by the germi-check advertisement of Pepsodent. With curiosity, they have recently heard of an experiment in the Biology Lab in a college for testing the effectiveness of it at inhibiting bacterial growth. From the experimental results, they concluded that Pepsodent toothpaste only killed or inhibited $50 \%$ of the bacteria. As a result, the germi-check advertisement of Pepsodent has backfired resulting in the choice of medicinal dental care pastes. This gap between brand identity and brand image of Pepsodent calls for a CARE-ing strategy (see Roy and Banerjee, 2007) to bridge the gap and an initiation for its resurrection in the Indian oral care market

The story of Close-up is different from that of Pepsodent. It is a case of positive experience, positive from the day one. It may be recalled that Close-up was test marketed in 1975 in select towns at a price premium of $43 \%$ over Colgate. It was the first Toothpaste-cum-Mouthwash product, in the form of a red, transparent gel. There was encouraging response from that test and five years later, the national brand was rolled out. It projected a westernized up-market urban description, where the favorers enjoyed the dual benefits of shiny white teeth and fresh breath. The launch reaped a modest but solid market. Close-up, despite being gel toothpaste, has been ranked the 10th most trusted brand in India, and has been a leader in the gel segment for over 25 years. Close-up is three times bigger than the number two brand in the gel category and is the third largest player in the toothpaste market according to a study conducted by ORG. Our in-depth interviews reveal that Indian young people are indeed conscious of how their breath smells when they are close with the opposite sex. Close-up has not only promised the fresher breath and whiter teeth but also promised them the confidence to be close with the persons who matter most. Our brand recall experiment has also confirmed that if we say 'gel' then more than eighty five percent people will say Close-up. If one mentions 'red, shiny paste' then again nearly same percentage of people will say Close-up. If one talks about 'oral care for confidence and romance' respondents can again unambiguously recognize Close-up. But in spite of its positive learning, Close-up has only managed to marginalize the weaker players without creating much impact on the bastion of Colgate. To become the number one in dental care market, it has a long way to go, to go beyond romance. Children and old people must also be targeted and well netted by Close-up to reach that ambitious end.

\section{References}

Ansoff ,H.I.(1987). Corporate Strategy, Penguin Books Ltd., McGraw Hill.

Bain, J. (1956). Barriers to New Competition, Harvard University Press, Cambridge, MA. 
Caminal, R., \& Vives, X. (1996). Why Market Shares Matter: An Information-Based Theory, Rand Journal of Economics, Vol.27, No.2, Summer, 221-239.

Carman, J. M. (1966). Brand switching and linear learning models, Journal of Advertising Research, Vol. 6, June issue, 23-31.

Danaher, P.J., Wilson, I.W., \& Davis, R. (2003). A Comparison of online and offline consumer brand loyalty, Marketing Science, Vol. 22, No.1, 461-475.

Ehrenberg, A. S. C., Uncles, M. D., \& Goodhardt, G. J. (2002). Understanding brand performance measures: Using Dirichlet benchmarks, Journal of Business Research, Vol. 57, Issue 12:9, 1307.

Ehrenberg, A.S.C. (1965). An Appraisal of Markov Brand Switching Models, Journal of Marketing Research, Vol.2, November, 347-62.

Guadagni , P., \& Little, J. (1983). A logit model of brand choice calibrated on scanner data, Marketing Science, Vol. 2 203-238.

Hill, C. W.L., \& Jones, G.R. (1992). Strategic Management Theory, Houghton Mifflin Company, Chapter 3.

Kolb, C., \& Rademeyer, A.(2005). An empirical analysis of Markov and logistic model predictive accuracy in the cellular market, SAMRA conference, May $11^{\text {th }}-14^{\text {th }} 2005$.

Kotler,P.(2000). Marketing Management: Analysis Planning and Control, 2000 millennium edition, Prentice -Hall, New Delhi (originally published in 1967).

Kuehn, A. A. (1962). Consumer Brand Choice-A Learning Process? Journal of Advertising Research Vol. 2,10-17.

Leeflang, P.S.H., \& Boonstra, A.(1982). Some comments on the development and application of linear learning models, Management Science, Vol. 26, November, 1233-46.

Lilien, G.L., Kotler, P., \& Moorthy, K.S.(1999). Marketing Models, Prentice- Hall, New Delhi. of Advertising Research Vol. 2,10-17.

Robert, C.P. \& Casella, G. (2004). Monte Carlo Statistical Methods, Springer.

Ross, S.M. (1983). Stochastic Processes, Wiley, New York.

Roy, D. \& Banerjee, S. (2007). Care-ing strategy for integration of brand identity with brand image, Accepted for publication in International Journal of Commerce and Management Vol.17, 140-148

Roy, D. \& Lahiri, I. (2004). Some tests for suitability of brand switching model, European Journal of Marketing, Vol.38 No. 5/6, 524-536.

Schwalbach, J. (1991). Profitability and Market Share: A reflection on the functional relationship, Strategic Management Journal, Vol.12, No.4, 299-306. 


\section{Macrothink}

Shannon, C.E. (1948). A Mathematical Theory of Communication, Bell System Tech. Journal, Vol.27, 379- 423 and 623- 665.

Slater,S.F. \& Nerver, J.C. (1994). Market orientation, customer value and superior performance, Business Horizons, March-April, 22-27.

Villas Boas (2004). Consumer Learning, Brand Loyalty, and Competition Marketing Science, Vol. 23(1), 134-145.

Wernerfelt, B. 1991. Brand loyalty and market equilibrium. Marketing Science, Vol. 10, 229-245.

Table 1. Loss Gain Matrix for Brand switching toothpaste

\begin{tabular}{|l|l|l|l|l|l|l|}
\hline Gain From & Colgate & Close-Up & Colgate Gel & Pepsodent & Others & Total \\
\hline Colgate & 124 & 17 & 5 & 4 & 23 & 173 \\
\hline Close up & 9 & 39 & 8 & 5 & 10 & 71 \\
\hline Colgate Gel & 6 & 5 & 30 & 2 & 6 & 49 \\
\hline Pepsodent & 10 & 6 & 4 & 16 & 4 & 40 \\
\hline Others & 19 & 10 & 6 & 5 & 27 & 67 \\
\hline Total & 168 & 77 & 53 & 32 & 70 & 400 \\
\hline
\end{tabular}

Table 2. Forward analysis for estimating market share's of different brands of toothpaste

\begin{tabular}{|l|l|l|l|l|l|}
\hline Gain from & Colgate & Close-up & Colgate Gel & Pepsodent & Others \\
\hline Colgate & .71676 & .09828 & .02890 & .02312 & .13294 \\
\hline Closeup & .12676 & .54929 & .11267 & .07042 & .14084 \\
\hline Colgate Gel & .12244 & .10204 & .61224 & .04081 & .12244 \\
\hline Pepsodent & .25 & .15 & .1 & .4 & .1 \\
\hline Others & .28358 & .14925 & .08955 & .07462 & .40298 \\
\hline
\end{tabular}




\section{Macrothink}

Table 3. Backward analysis for estimating market share's of different brands of toothpaste

\begin{tabular}{|l|l|l|l|l|l|}
\hline $\begin{array}{l}\text { Gain } \\
\text { from }\end{array}$ & Colgate & Close-up & Colgate Gel & Pepsodent & Others \\
\hline Colgate & .73809 & .22077 & .09433 & .125 & .32857 \\
\hline Close-up & .05357 & .50649 & .15094 & .15625 & .14285 \\
\hline $\begin{array}{l}\text { Colgate } \\
\text { Gel }\end{array}$ & .03571 & .06493 & .56603 & .0625 & .08571 \\
\hline Pepsodent & .05952 & .07792 & .07547 & .5 & .05714 \\
\hline Others & .11309 & .12987 & .11320 & .15625 & .38571 \\
\hline
\end{tabular}

Table 4. Brand-wise Backward and Forward steady state market share

\begin{tabular}{|l|l|l|}
\hline Toothpaste & $\begin{array}{l}\text { Backward steady state } \\
\text { market share, } \mathbf{X}^{\mathbf{B}}\end{array}$ & ${\underset{\mathbf{X}}{\mathbf{F}}}^{\mathbf{F}}$ \\
\hline Colgate & .4428 & .3981 \\
\hline Closeup & .1662 & .2033 \\
\hline Colgate-gel & .1106 & .1483 \\
\hline Pepsodent & .1143 & .0714 \\
\hline Others & .1661 & .1789 \\
\hline
\end{tabular}

